\title{
The Immunoconjugate "Icon" Targets Aberrantly Expressed Endothelial Tissue Factor Causing Regression of Endometriosis
}

\author{
Graciela Krikun, ${ }^{*}$ Zhiwei Hu, ${ }^{*}$ Kevin Osteen, ${ }^{\dagger}$ \\ Kaylon L. Bruner-Tran, ${ }^{\dagger}$ Frederick Schatz, ${ }^{*}$ \\ Hugh S. Taylor, ${ }^{*}$ Paolo Toti, ${ }^{\ddagger}$ Felice Arcuri, ${ }^{\ddagger}$ \\ William Konigsberg, ${ }^{\S}$ Alan Garen, ${ }^{\S}$ \\ Carmen J. Booth, ${ }^{\pi}$ and Charles J. Lockwood* \\ From the Department of Obstetrics, Gynecology, and \\ Reproductive Sciences, "Molecular Biophysics and Biochemistry, $\$$ \\ and the Section of Comparative Medicine, "Yale University, \\ School of Medicine, New Haven, Connecticut; the Department of \\ Obstetrics and Gynecology, ${ }^{\dagger}$ Vanderbilt University Medical \\ Center, Nashville, Tennessee; and the Department of Human \\ Pathology and Oncology, ${ }^{\ddagger}$ University of Siena, Siena, Italy
}

Endometriosis is a major cause of chronic pain, infertility, medical and surgical interventions, and health care expenditures. Tissue factor (TF), the primary initiator of coagulation and a modulator of angiogenesis, is not normally expressed by the endothelium; however, prior studies have demonstrated that both blood vessels in solid tumors and choroidal tissue in macular degeneration express endothelial TF. The present study describes the anomalous expression of TF by endothelial cells in endometriotic lesions. The immunoconjugate molecule (Icon), which binds with high affinity and specificity to this aberrant endothelial TF, has been shown to induce a cytolytic immune response that eradicates tumor and choroidal blood vessels. Using an athymic mouse model of endometriosis, we now report that Icon largely destroys endometriotic implants by vascular disruption without apparent toxicity, reduced fertility, or subsequent teratogenic effects. Unlike antiangiogenic treatments that can only target developing angiogenesis, Icon eliminates pre-existing pathological vessels. Thus, Icon could serve as a novel, nontoxic, fertility-preserving, and effective treatment for endometriosis. (Am J Pathol 2010, 176:1050-1056; DOI: 10.2353/ajpath.2010.090757)
Endometriosis is a gynecological disorder characterized by the presence of functional endometrial tissue outside of the uterus. ${ }^{1}$ The disease affects up to $10 \%$ of all reproductive-age women and up to $50 \%$ of infertile women. ${ }^{1-3}$ Endometriotic lesions are primarily located on the pelvic peritoneum and ovaries, but can also be found in the colon, pericardium, pleura, lung parenchyma, and brain. ${ }^{2}$ Implants can cause pelvic adhesions, chronic pelvic pain, bowel obstruction, and infertility requiring repetitive, extensive, and expensive medical and surgical treatments. $^{1,4,5}$

The etiology of the disease has been ascribed to retrograde menstruation, coelomic metaplasia, or both. ${ }^{1,6-9}$ Although its pathogenesis involves a complex interplay of genetic, anatomical, environmental, and immunological factors, there is general agreement that it is associated with a local inflammatory response and that vascularization at the site of ectopic attachment of the lesions is a key determinant in its pathogenesis. ${ }^{1,10-13}$ Angiogenic agents such as vascular endothelial growth factor and the angiopoietins are likely mediators of endometriotic neovascularization. ${ }^{1,3,11-13}$

Tissue factor (TF), the transmembrane initiator of hemostasis, is not physiologically expressed by endothelial cells but plays a crucial role in embryonic and oncogenic angiogenesis. ${ }^{14-17}$ Recent studies indicate that the type-2 proteinase activated receptor (PAR-2) is intimately involved in TF-mediated signaling and angiogenesis. ${ }^{15,18,19}$ Tissue factor may initiate differential signaling pathways in physiological compared with pathological angiogenesis, ${ }^{20}$ to wit, the physiological pathway is mediated by TF-thrombin-PAR-1 and the pathological pathway by TF/factor FVIIa/PAR-2 signaling. ${ }^{20}$ These latter vessels display abnormal structure and function and are

Supported in part by grants from the NIH U54HD052668, and the Swebilius Translational Cancer Research Award from Yale Cancer Center (to Z.H.)

Accepted for publication October 27, 2009.

Address reprint requests to Dr. Graciela Krikun or Dr. Zhiwei Hu, Department of Obstetrics, Gynecology, and Reproductive Sciences, Yale University, School of Medicine, 333 Cedar St., PO Box 208063, New Haven, CT 06520-8063. E-mail: graciela.krikun@yale.edu or zhiwei.hu@yale.edu 
poorly associated with pericytes causing leakiness and edema. ${ }^{21,22}$

Our prior studies demonstrated that both TF and PAR-2 are up-regulated in endometria of women with endometriosis compared with unaffected women. ${ }^{23}$

In this report, we describe the anomalous endothelial expression of TF in ectopic endometrium derived from women with endometriosis. We posited that a novel chimeric immunoconjugate molecule (Icon) will specifically target endothelial TF in ectopic implants leading to their devascularization and atrophy. Icon is composed of a mutated low-coagulation-inducing factor VII (fVII) domain that binds to TF with high affinity and an IgG1 FC (fVII/lgG1 FC) effector domain that activates a natural killer cell cytolytic response against TF bearing endothelial cells. ${ }^{24-27}$ This report confirms our hypothesis by demonstrating that Icon largely destroys pre-established human endometriotic lesions in an athymic mouse model without untoward systemic effects, altered fertility, or subsequent teratogenesis.

\section{Materials and Methods}

\section{Tissues}

Control eutopic endometrial tissues were obtained from consenting fertile reproductive-age women free of clinical endometriosis undergoing endometrial sampling at the time of tubal ligation with five samples from the proliferative phase and five from the secretory phase. The age range was 29 to 38 years. Eutopic and ectopic endometria were obtained from women diagnosed with endometriosis at operative laparoscopy for chronic pelvic pain and/or infertility. In all subjects, endometriotic implants were resected and the diagnosis confirmed by histopathology $(n=6)$. Subjects were staged according to the revised American Fertility Society classification and were either in the mid to late proliferative phase. ${ }^{28}$ None of the subjects were treated with hormones in the two months preceding surgery. Patient age range was 27 to 49 years. All subjects provided informed consent, and this study was approved by the Yale University School of Medicine Human Investigation Committee as well as the Vanderbilt University Institutional Review Board and Committee for the Protection of Human Subjects.

\section{Immunohistochemistry}

Formalin-fixed paraffin-embedded tissues were cut in 5-micron sections. Immunohistochemistry was performed as previously described. ${ }^{29,30}$ For confirmatory purposes, two antibodies to TF were used, a polyclonal antibody to human TF (hTF; R\&D Systems, Minneapolis, MN) and a monoclonal antibody produced by one of the authors (W.K.). Both antibodies displayed identical staining patterns. The antibody to von Willebrand factor (VWF) Ab6994 (Abcam, Cambridge, MA), an endothelial cell marker, recognized both human and mouse antigens. Specific staining of vessels for vWF was used to quantify vessel density by using Image $\mathrm{J}$ public domain software.
Negative controls were conducted with an appropriate pre-immune serum. Detection of Icon used anti-human IgG (Vector Laboratories, Burlingame, CA) directed against the Fc potion of Icon. Sections were analyzed by digitally capturing a minimum of three fields per slide.

\section{Icon}

Mouse Icon protein was synthesized by stable transfection of Chinese hamster ovary $(\mathrm{CHO})$ cells as previously described ${ }^{24-26}$ with modifications as follows. The transfected $\mathrm{CHO}$ cells were cultured in serum-free EXCELL $301 \mathrm{CHO}$ medium (JRH Biosciences, Lenexa, KS) supplemented with a final concentration of $1 \mu \mathrm{g} / \mathrm{ml}$ of vitamin K1 (Sigma-Aldrich, St. Louis, MO). The Icon protein was purified from the culture medium by affinity chromatography on a HiTrap rProtein A FF $5 \mathrm{ml}$ column (Amersham Biosciences, Piscataway, NJ), dialyzed against $10 \mathrm{mmol} / \mathrm{L}$ HEPES pH 7.4, $150 \mathrm{mmol} / \mathrm{L} \mathrm{NaCl}_{2}$, and $5 \mathrm{mmol} / \mathrm{L} \mathrm{CaCl}_{2}$, and then concentrated with a Millipore filter with a cutoff molecular weight of 100,000 kDa (Millipore, Billerica, MA). The final concentration of the Icon was determined with the Bradford assay reagent (Bio-Rad, Hercules, CA). The Icon is composed of two mature coagulation fVII peptides containing a mutation of Lys341 to Ala. Thus Icon is a natural ligand for TF, in which the mutated fVII is fused to the Fc domain of a human IgG1 antibody by recombinant DNA technology. ${ }^{25,26}$ The introduction of a mutation in the fVII portion of mouse and human Icon molecules was used to reduce their coagulation activity ${ }^{25}$ while retaining the binding activity to TF as previously reported. ${ }^{25,31}$

The Icon molecule is designed to bind to TF with far higher affinity and specificity than can be achieved with an anti-TF antibody. The Icon has several important advantages over monoclonal antibodies for targeting TF including: (1) The $\mathrm{kDa}$ for fVII binding to TF is up to $10^{-12}$ $\mathrm{mol} / \mathrm{L},{ }^{32}$ whereas anti-TF antibodies have a $\mathrm{kDa}$ in the range of $10^{-8}$ to $10^{-9} \mathrm{~mol} / \mathrm{L}^{33,34}$; (2) The Icon is produced by recombinant DNA technology, allowing for the generation mouse Icon (mouse $\mathrm{fVII} /$ human IgG1 Fc) for use in murine models of human diseases and human Icon (human $\mathrm{fVII} /$ human IgG1 Fc) for future clinical trials. Moreover, Icon obviates the necessity of generating humanized monoclonal antibodies. The basic principle of Icon therapy is that TF is inappropriately expressed by the endothelium of vessels in pathological tissues, and Icon targets this aberrant TF expression and induces an natural killer-mediated immune response that devascularizes the lesion.

\section{Conjugation of Mouse Icon Protein with Fluorescein Isothiocyanate}

Mouse Icon protein was conjugated with fluorescein isothiocyanate (FITC) using the Pierce FITC antibody labeling kit (Thermo Scientific, Waltham, MA) following the manufacturer's instruction. Free dye was separated from the protein-conjugated FITC using resin and the conjugated FITC collected. The ratio of FITC to mouse Icon protein, calculated by measuring A280 $\mathrm{nm}$ for protein 
concentration and A495 nm for FITC concentration, was 3.5:1. Flow cytometry demonstrated that Icon-FITC conjugate bound a human melanoma TF2 cell line expressing high levels of TF. ${ }^{35}$ Immunofluorescent staining for CD31 and DAPI was conducted as previously described. ${ }^{36}$ The aim of Icon conjugation with FITC is to colocalize Icon binding to the CD31-positive endothelial cells.

In the colocalization study of Icon and CD31 expression, $10 \mu \mathrm{g}$ of mouse FITC-conjugated Icon protein was injected into the peritoneal cavity (IP) of 12 athymic nude (ATN) mice, implanted with human endometrial tissues 12 days before FITC-Icon treatment. Controls were similarly injected IP with saline $(n=3)$. The endometrial lesions were removed from the FITC-Icon injected mice and from control mice at 4,8 , and 24 hours $(n=3)$ at each time point.

\section{Athymic Nude Mouse Model}

Endometrial tissues were acquired by Pipelle ${ }^{\circledR}$ biopsy (Unimar, Inc., Wilton, CT) from consenting healthy women during the proliferative phase (days 9 to 12) of the menstrual cycle $(n=5)$. The age range of the women spanned 36 to 41 years with a mean age of 38 years. All tissues were obtained from the mid to late proliferative phase of the menstrual cycle. An endometrial thickness $\geq 9 \mathrm{~mm}$ (confirmed by vaginal ultrasound) and a serum progesterone level of $<1.5 \mathrm{ng} / \mathrm{ml}$ were required for inclusion in this study. Individuals with a history of hormone therapy (eg, gonadotropin-releasing hormone antagonist, oral contraceptives) within two months were excluded. Biopsies were washed in prewarmed phenol-red free Dulbecco's Modified Eagles Medium/Ham's F-12 Medium (DME/F-12; Sigma-Aldrich) to remove residual blood and mucous before culturing. Endometrial biopsies were dissected into small cubes $\left(\approx 1 \times 1 \mathrm{~mm}^{3}\right)$ and 8 to 10 pieces of tissue per mouse were suspended in tissue culture inserts (Millipore, Bedford MA). Organ cultures were maintained for 18 to 24 hours before injection into mice under serum-free conditions in DME/F-12 supplemented with $1 \%$ Insulin-Transferrin-Selenium (ITS+; Collaborative Biomedical, Bedford MA), 0.1\% Excyte (Miles Scientific, Kankakee IL), and $1 \mathrm{nmol} / \mathrm{L} 17 \beta$-estradiol (E2; Sigma-Aldrich). Cultures were incubated at $37^{\circ} \mathrm{C}$ in a humidified chamber with $5 \% \mathrm{CO} 2$.

The model of endometriosis used in the current study has been previously described and validated. ${ }^{37}$ Briefly, six-week-old female ovariectomized ATN mice (Harlan Laboratories, Indianapolis, IN) were anesthetized with isoflurane (Henry Schein, Melville, NY) and subcutaneously implanted with a silastic capsule (Dow Corning Silastic Laboratory Tubing, 1/16 in. I.D.; 1/8 in. O.D.; Wall Thickness: 1/32 in.) containing $8 \mathrm{mg}$ E2 in cholesterol (Sigma-Aldrich). The ends of the silastic tubes were sealed with Type A medical silicone adhesive (Factor II, Inc., Lakeside, AZ). Twenty-four hours after subcutaneous placement of the silastic capsules, mice received an IP injection of PBS containing a suspension of 8 to 10 human endometrial tissue fragments per mouse into the ventral midline just below the umbilicus. Treatment with
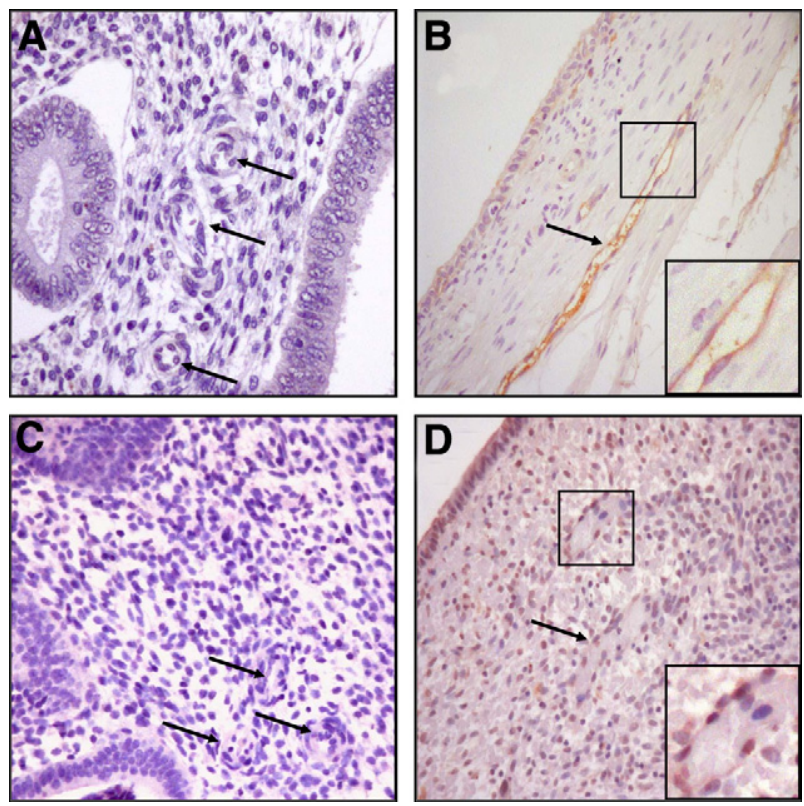

Figure 1. Expression of TF in endothelial cells from human ectopic endometrium: Immunohistochemistry was performed as described in the Methods. Eutopic proliferative endometrium from patients with endometriosis showing low to no TF staining in glands or stromal cells; vessels walls and endothelial cells are unstained (arrows) (original magnification, $\times 100$; $\mathbf{A}$ and $\mathbf{C}$ ); ectopic endometriotic implants from the same patients, respectively, displaying strong TF immunostaining in endothelial cells (arrows) with moderate TF immunostaining of ectopic glands and stromal cells (original magnification, $\times 100 ; \mathbf{B}$ and $\mathbf{D}) .(n=6)$.

Icon was initiated 10 to 12 days after the injection of tissue. Controls consisted of animals treated with saline or nonspecific murine IgG. After completion of the treatment regimen, mice were sacrificed by cervical dislocation under anesthesia and direct examination of intraperitoneal lesion size and number were determined. Lesions were measured in two dimensions; the largest denoted "a" and the smallest denoted "b." The total volume of lesions was calculated by standard methodology ${ }^{38}$ using the formula: $V=a \times 2 b \times 0.5$. We conducted 5 separate studies using 5 endometrial biopsies. Each study used the biopsy from one patient. Because biopsies varied in size, the number of mice varied. Studies 1 to 5 used 10, $10,12,14$, and 7 mice, respectively. We did not mix samples from different women. Residual lesions were removed and formalin-fixed/paraffin-embedded for analysis. Experiments described herein were approved by Vanderbilt University Instructional Animal Care and Use Committee in accordance with the Animal Welfare Act.

Table 1. Effect of Icon Treatment on Mice with Endometriotic Lesions

\begin{tabular}{|c|c|c|c|c|c|}
\hline Mouse Tx & $\begin{array}{c}\text { Avg. vessel } \\
\text { size } \\
\text { (arbitrary units) }\end{array}$ & $P$ & $\begin{array}{c}\text { No. of mice } \\
\text { with disease } \\
\text { per total } \\
\text { number }\end{array}$ & $\begin{array}{l}\% \text { with } \\
\text { disease }\end{array}$ & $P$ \\
\hline $\begin{array}{l}\text { Control } \\
\text { Icon }(5 \mu \mathrm{g}) \\
\text { Icon }(10 \mu \mathrm{g})\end{array}$ & $\begin{array}{l}2.88 \\
1.21 \\
1.50\end{array}$ & $\begin{array}{l}<0.05 \\
<0.05\end{array}$ & $\begin{array}{r}12 / 13 \\
7 / 12 \\
4 / 15\end{array}$ & $\begin{array}{l}92 \% \\
58 \% \\
27 \%\end{array}$ & $\begin{array}{c}\text { NS } \\
<0.05\end{array}$ \\
\hline
\end{tabular}

All mice were treated as described in Methods. $P$ refers to the leve of significance. 

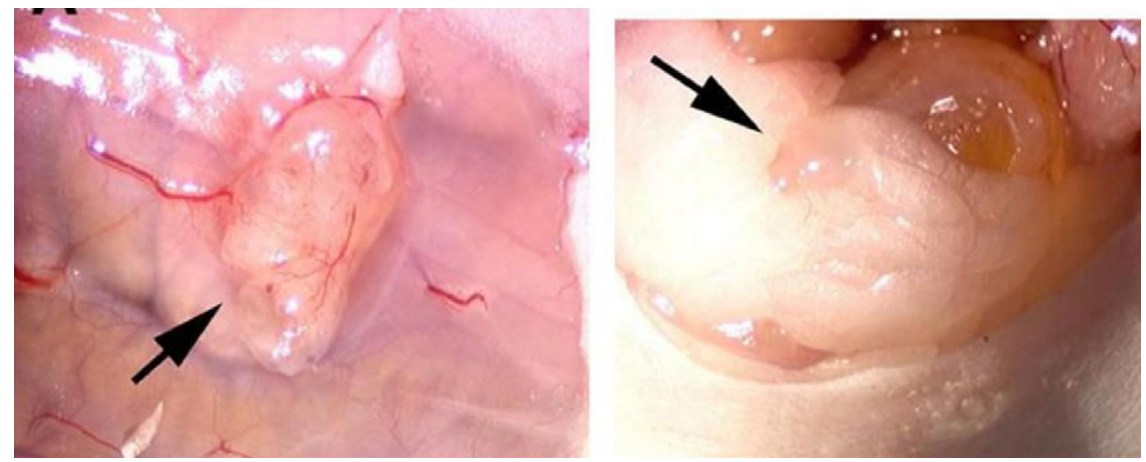

Figure 2. Gross morphological analysis: Representative lesions from placebo (left) or $10-\mu \mathrm{g}$ Icon-treated (right) ATN mice with established human endometriotic lesions displaying obvious differences in gross surface vascularization $(n=15)$. Arrows point to the lesions.

\section{Toxicity, Fertility, and Teratogenicity Studies}

Female ATN mice were treated IP with either Icon or vehicle control once a week for four weeks ( $n=4$ per group). Two weeks after the last injection, the mice were allowed to breed. Pregnancy was determined by a vaginal plug. For these experiments, adult and neonatal mice were euthanized by carbon dioxide inhalation. Mice were necropsied and tissues evaluated blinded to the experimental manipulation. All of the tissues were harvested from each adult mouse and fetus/neonate. Whole fetuses, pups, and adults, their respective sterna, one rear leg, and head with skull cap and skin removed were placed in Bouin's Fixative (VWR International, Batavia IL). The remaining adult mouse tissues were placed in 10\% Neutral Buffered Formalin (VWR International, Batavia IL). A routine selection of tissues from all organ systems in adult mice were chosen for histopathological examination. Two fetuses and two neonatal pups were selected from each litter for histopathological examination. All selected tissues were processed, embedded in paraffin, sectioned to 5 microns, and stained with hematoxylin and eosin (H\&E) (Sigma-Aldrich). All mice were examined visually at necropsy for macroscopic lesions and all tissue sections were examined using light microscopy for experimentally induced pathological changes.

\section{Results}

\section{Immunohistochemistry}

Figure 1, A-D demonstrates a failure to detect endothelial TF by immunostaining in proliferative eutopic endometrium (Figure 1, A and C), whereas ectopic endometrium from the same patient displays strong immunostaining for endothelial TF (Figure 1, B and D). This finding of high TF expression by endometrial ectopic endothelium led us to determine whether administration of the TF-targeting Icon molecule would eliminate such implants in a mouse model of endometriosis.

\section{Treatment of Endometriosis with Icon in a Murine Model}

The ATN mice were injected with approximately $1.0 \mathrm{ml}$ packed endometrial tissue and treated as described in Methods. On gross morphological examination, 11 of 15 treated mice had no sign of residual disease after 4 weekly $10-\mu \mathrm{g}$ Icon treatments compared with 5 of 12 mice treated with a $5-\mu \mathrm{g}$ Icon dose. By contrast, 12 of 13 mice treated with vehicle control had well-defined endometrial lesions (Table 1). Residual lesions in Icon-treated mice were significantly smaller than those found in con-

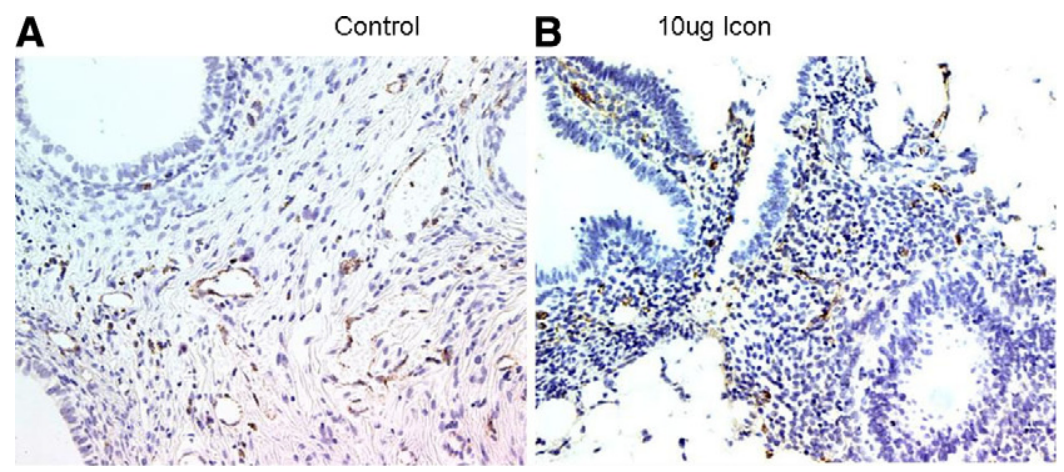

C

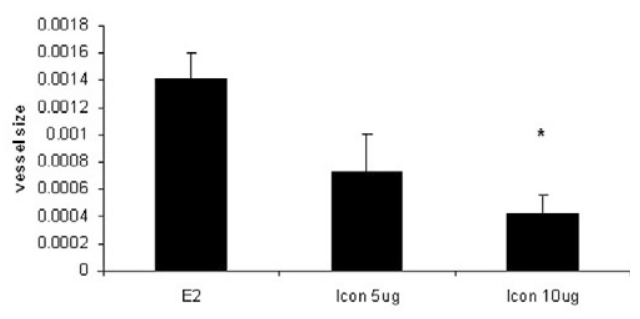

Figure 3. Microscopic endometriotic vessel analysis: Vessels in human peritoneal endometriotic implants present in ATN mice were visualized by immunohistochemical staining for vWF after treatment with vehicle control (A) or $10 \mu \mathrm{g}$ Icon $(\mathbf{B} ; n=5, \times 200)$. C: Morphometric analysis demonstrated that both 5 and 10 $\mu \mathrm{g}$ Icon resulted in a significant decrease in vessel size in mice with residual lesions. Vessel size is reported in arbitrary units. Statistical analysis was conducted by analysis of variance $\left(n=5,{ }^{*} P<0.05\right)$. 

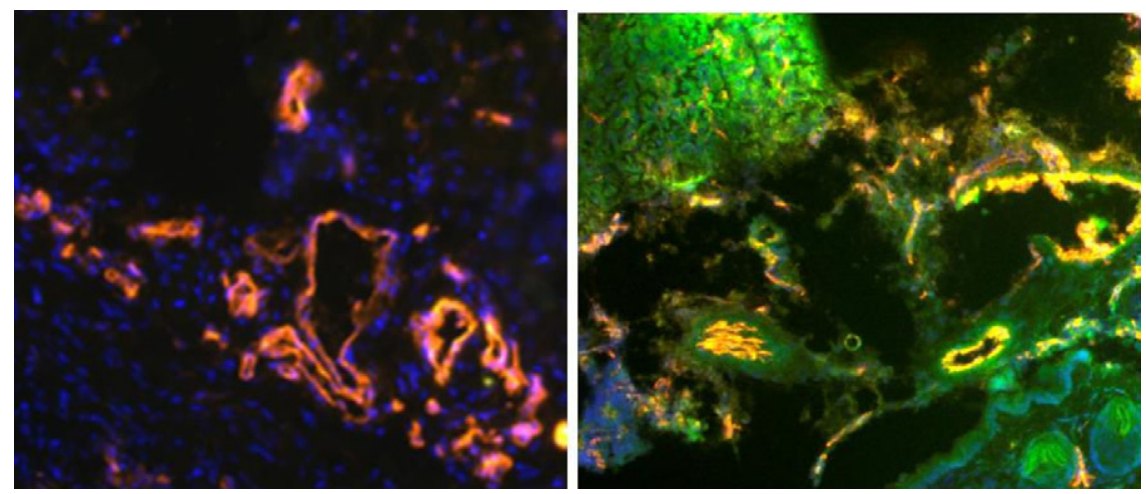

Figure 4. Immunofluorescence for Icon: Human endometrium recovered from control treated mouse was immunostained consecutively for CD31 (detected with phycoerythrin) and DAPI (blue; left). Endometriotic lesion in an ATN mouse extracted four hours after injection with FITC-labeled Icon (green) were also stained with CD31 and DAPI (right). $(\times 400, n=3)$.

trol animals (Table 1), and it was difficult to observe any vascularization (Figure 2).

To quantify the effects of 5 - or $10-\mu \mathrm{g}$ Icon treatments versus vehicle control on vessel morphology, lesions were removed, formalin-fixed, and paraffin-embedded as described in Methods. Immunohistochemistry with an antibody against vWF was used to detect vascular endothelium. As shown in Figure 3, treatment with $10 \mu \mathrm{g}$ Icon resulted in vessels that were quantitatively smaller in caliber with an aberrant appearance compared with controls. Vessel number and size were then assessed by the public domain software Image $J$ in mice treated with either vehicle control, or 5 or $10 \mu \mathrm{g}$ of Icon. Treatment with $10 \mu \mathrm{g}$ Icon resulted in a statistically significant decrease in vessel size compared with saline treated controls (Figure 3C).

To confirm the tissue localization of Icon binding in the mouse endometriosis model, FITC-conjugated Icon (10 $\mu \mathrm{g})$ or vehicle control was injected IP for 4,8 , and 24 hours ( $n=6$ at each time point). Figure 4 indicates that no FITC fluorescence was detected in control mice, whereas blood vessels stain red (mouse-CD31) and the nuclei stain blue (DAPI). By contrast, tissues extracted four hours after injection of FITC labeled Icon (green) show all three colors, colocalization of red and green dyes in endothelium is indicated by the color yellow, supporting the conclusion that Icon disrupts endometriotic lesions by targeting the vascular endothelium.

\section{Toxicity, Fertility, and Teratogenicity Studies}

The systemic and reproductive effects of prior Icon treatment $(10 \mu \mathrm{g})$ on fertility were conducted as described in Methods. We observed that ATN mice treated with Icon once a week for four weeks conceived normally and had the same pregnancy rates as control ATN mice. Figure 5 demonstrates that the average number of viable embryos/ live born pups was 8.25 per litter for control and 8.5 for mice previously treated with Icon; similar to the reported average litter size of seven for ATN (personal communication, March 25, 2009, Jay Aeyers Harlan Laboratories Technical Support). All pregnancies progressed normally. Histopathological examination of tissues from control and Icon-treated adult pregnant or postpartum female ATN mice showed no systemic or reproductive tract pathology. Specifically, heart, lung, brain, liver, kidney, spleen, bone, muscle, or Gl tract displayed no pathological abnormalities in either treated or untreated animals. All embryos and postnatal day 1 mice collected at less than six hours after birth from control and Icon-treated mice appeared grossly and histologically normal with no evidence of teratogenic effects. All embryos and postnatal day 1 mice collected at less than six hours after birth from control and Icon-treated mice appeared grossly and histologically normal. All pups fed and milk contents were visible in their stomach.

\section{Discussion}

Prior studies from our laboratory demonstrated that in normal endometrium, progestin markedly enhanced TF protein and mRNA expression in decidualized stromal cells during the luteal phase and in decidual cells through term. ${ }^{30,39-41}$ We have also shown that glandular epithelial cells display minimal TF expression throughout the menstrual cycle. ${ }^{30,39,40}$ The present study sought to determine the pattern and extent of TF expression in endometriosis and observed anomalous endothelial expression of TF in ectopic versus eutopic endometrium. This expression likely reflects the strong association of endometriosis with increased inflammatory cytokine production. ${ }^{3,42,43}$ Interleukin- $1 \beta$ and tumor necrosis factor- $\alpha$ acting via the NF $\kappa$ B transcription factor increase TF gene expression in endothelial cells from various tissues. ${ }^{44}$ Increased TF expression in endometrial endothelial cells may also reflect genetic polymorphisms in the promoter

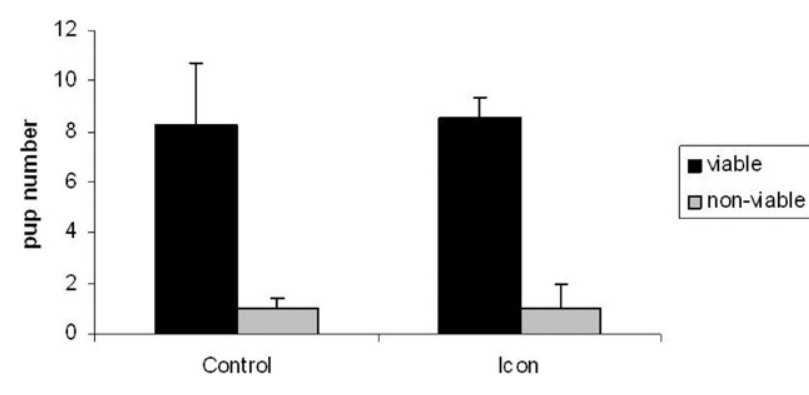

Figure 5. Fertility studies: ATN mice were treated with Icon or placebo once a week for four weeks. Two weeks after the last Icon treatment, mice were mated. All mice conceived. The average number of viable pups is shown in dark bars, whereas the number of nonviable pups is shown in light bars ( $n=$ 4 per group; $\left.{ }^{*} P<0.05\right)$. 
region of genes known to regulate TF expression as well as the TF promoter region. ${ }^{45-47}$

The aberrant expression of TF in ectopic endometrial endothelium suggested that this TF expression might be an ideal therapeutic target for endometriosis. Toward this end, we used the immunoconjugate molecule, Icon, in a mouse model of endometriosis. Previous studies demonstrated that Icon targeted TF that was aberrantly expressed by endothelial cells in malignant tumors. ${ }^{24-26}$ Icon also reduced the formation of pathological choroidal neovasculature associated with macular degeneration. ${ }^{48,49}$ Thus, Icon specifically targets endothelial TF expression in pathological vasculature while having no effects on normal vessels. In this study we demonstrate that Icon therapy largely destroys previously established and well-vascularized human endometriotic lesions in a mouse model of endometriosis. Because spontaneous endometriosis occurs only in women and in nonhuman primates, future studies will hopefully involve an animal model that mimics the human disease as described by D'Hooghe and coworkers. ${ }^{50}$

Importantly, because Icon targets not only neoangiogenesis, but pre-existing vessels aberrantly expressing TF in their endothelium, it is the only available agent with the potential to successfully treat pre-existent well-vascularized lesions. This is an important point, as women suffering from endometriosis are typically not diagnosed for several years ${ }^{51,52}$ and thus would already have established lesions. Although several treatments for endometriosis are available, they are associated with high recurrence rates and considerable side effects. ${ }^{53}$ Prior studies have confirmed that Icon treatment does not produce toxicity in various animal species, ${ }^{24,26,48,49,54}$ and we confirm no untoward effects on adult mice treated with Icon. In addition, we now report that Icon treatment does not interfere with subsequent fertility nor does it give rise to teratogenic effects. Hence, Icon may be an ideal drug of choice in the treatment of endometriosis and in particular for reproductive-age women suffering with this disease who desire subsequent fertility.

\section{References}

1. Giudice LC, and Kao LC. Endometriosis. Lancet 2004, 364:1789-1799

2. Sharpe-Timms KL, and Young SL: Understanding endometriosis is the key to successful therapeutic management. Fertil Steril 2004, 81:1201-1203

3. Taylor RN, Lebovic DI, and Mueller MD: Angiogenic factors in endometriosis. Ann NY Acad Sci 2002, 955:89-100; discussion 118:396-406

4. Nezhat C, Crowgey SR, and Garrison CP: Surgical treatment of endometriosis via laser laparoscopy and videolaseroscopy. Contrib Gynecol Obstet 1987, 16:303-312

5. Surrey ES, and Schoolcraft WB: Management of endometriosis-associated infertility. Obstet Gynecol Clin North Am 2003, 30:193-208

6. Gazvani R, and Templeton A: New considerations for the pathogenesis of endometriosis. Int J Gynaecol Obstet 2002, 76:117-126

7. Haney AF: Etiology and histogenesis of endometriosis. Prog Clin Biol Res 1990, 323:1-14

8. Ishimura $\mathrm{T}$, and Masuzaki $\mathrm{H}$ : Peritoneal endometriosis: endometrial tissue implantation as its primary etiologic mechanism. Am J Obstet Gynecol 1991, 165:210-214

9. Oral E, and Arici A: Pathogenesis of endometriosis. Obstet Gynecol Clin North Am 1997, 24:219-233
10. Fujimoto J, Sakaguchi H, Hirose R, Wen H, and Tamaya T: Angiogenesis in endometriosis and angiogenic factors. Gynecol Obstet Invest 1999, 48:14-20

11. Li XF, Charnock-Jones DS, Zhang E, Hiby S, Malik S, Day K, Licence D, Bowen JM, Gardner L, King A, Loke YW, and Smith SK: Angiogenic growth factor messenger ribonucleic acids in uterine natural killer cells. J Clin Endocrinol Metab 2001, 86:1823-1834

12. Mahnke JL, Dawood MY, and Huang JC: Vascular endothelial growth factor and interleukin-6 in peritoneal fluid of women with endometriosis. Fertil Steril 2000, 73:166-170

13. McLaren J, Prentice A, Charnock-Jones DS, Millican SA, Muller KH, Sharkey AM, and Smith SK: Vascular endothelial growth factor is produced by peritoneal fluid macrophages in endometriosis and is regulated by ovarian steroids. J Clin Invest 1996, 98:482-489

14. Carmeliet $P$, Mackman N, Moons L, Luther $T$, Gressens $P$, Van Vlaenderen I, Demunck H, Kasper M, Breier G, Evrard P, Muller M, Risau W, Edgington T, and Collen D: Role of tissue factor in embryonic blood vessel development. Nature 1996, 383:73-75

15. Versteeg HH, Peppelenbosch MP, and Spek CA: Tissue factor signal transduction in angiogenesis. Carcinogenesis 2003, 24:1009-1013

16. Bugge TH, Xiao Q, Kombrinck KW, Flick MJ, Holmback K, Danton MJ, Colbert MC, Witte DP, Fujikawa K, Davie EW, and Degen JL: Fatal embryonic bleeding events in mice lacking tissue factor, the cellassociated initiator of blood coagulation. Proc Natl Acad Sci USA 1996, 93:6258-6263

17. Toomey JR, Kratzer KE, Lasky NM, Stanton JJ, and Broze GJ Jr. Targeted disruption of the murine tissue factor gene results in embryonic lethality. Blood 1996, 88:1583-1587

18. Chand HS, Ness SA, and Kisiel W: Identification of a novel human tissue factor splice variant that is upregulated in tumor cells. Int $J$ Cancer 2006, 118:1713-1720

19. Mackman N: Gene targeting in hemostasis. tissue factor. Front Biosci 2001, 6:D208-D215

20. Belting M, Dorrell MI, Sandgren S, Aguilar E, Ahamed J, Dorfleutner A, Carmeliet P, Mueller BM, Friedlander M, and Ruf W: Regulation of angiogenesis by tissue factor cytoplasmic domain signaling. Nat Med 2004, 10:502-509

21. Joussen AM: Vascular plasticity-the role of the angiopoietins in modulating ocular angiogenesis. Graefes Arch Clin Exp Ophthalmol 2001 239:972-975

22. Ghosh K, Thodeti CK, Dudley AC, Mammoto A, Klagsbrun M, and Ingber DE: Tumor-derived endothelial cells exhibit aberrant Rhomediated mechanosensing and abnormal angiogenesis in vitro. Proc Natl Acad Sci USA 2008, 105:11305-11310

23. Krikun G, Schatz F, Taylor H, and Lockwood CJ: Endometriosis and tissue factor. Ann NY Acad Sci 2008, 1127:101-105

24. Hu Z, and Garen A: Intratumoral injection of adenoviral vectors encoding tumor-targeted immunoconjugates for cancer immunotherapy. Proc Natl Acad Sci USA 2000, 97:9221-9225

25. Hu Z, and Garen A: Targeting tissue factor on tumor vascular endothelial cells and tumor cells for immunotherapy in mouse models of prostatic cancer. Proc Natl Acad Sci USA 2001, 98:12180-12185

26. Hu Z, Sun Y, and Garen A: Targeting tumor vasculature endothelial cells and tumor cells for immunotherapy of human melanoma in a mouse xenograft model. Proc Natl Acad Sci USA 1999, 96:8161-8166

27. Osteen KG, Bruner-Tran KL, Ong D, and Eisenberg E: Paracrine mediators of endometrial matrix metalloproteinase expression: potential targets for progestin-based treatment of endometriosis. Ann NY Acad Sci 2002, 955:139-146; discussion 157-158, 396-406

28. 1997. Revised American Society for Reproductive Medicine classification of endometriosis. Fertil Steril 1996, 67:817-821

29. Krikun G, Critchley H, Schatz F, Wan L, Caze R, Baergen RN, and Lockwood CJ: Abnormal uterine bleeding during progestin-only contraception may result from free radical-induced alterations in angiopoietin expression. Am J Pathol 2002, 161:979-986

30. Lockwood CJ, Nemerson Y, Guller S, Krikun G, Alvarez M, Hausknecht V, Gurpide E, and Schatz F: Progestational regulation of human endometrial stromal cell tissue factor expression during decidualization. J Clin Endocrinol Metab 1993, 76:231-236

31. Dickinson CD, Kelly CR, and Ruf W: Identification of surface residues mediating tissue factor binding and catalytic function of the serine protease factor VIla. Proc Natl Acad Sci USA 1996, 93:14379-14384

32. Waxman E, Ross JB, Laue TM, Guha A, Thiruvikraman SV, Lin TC, Konigsberg $\mathrm{WH}$, and Nemerson $\mathrm{Y}$ : Tissue factor and its extracellular 
soluble domain: the relationship between intermolecular association with factor VIla and enzymatic activity of the complex. Biochemistry 1992, 31:3998-4003

33. Presta L, Sims P, Meng YG, Moran P, Bullens S, Bunting S, Schoenfeld J, Lowe D, Lai J, Rancatore P, Iverson M, Lim A, Chisholm V, Kelley RF, Riederer M, and Kirchhofer D: Generation of a humanized, high affinity anti-tissue factor antibody for use as a novel antithrombotic therapeutic. Thromb Haemost 2001, 85:379-389

34. Kirchhofer D, Moran P, Chiang N, Kim J, Riederer MA, Eigenbrot C, and Kelley RF: Epitope location on tissue factor determines the anticoagulant potency of monoclonal anti-tissue factor antibodies. Thromb Haemost 2000, 84:1072-1081

35. Bromberg ME, Konigsberg WH, Madison JF, Pawashe A, and Garen A: Tissue factor promotes melanoma metastasis by a pathway independent of blood coagulation. Proc Natl Acad Sci USA 1995, 92:8205-8209

36. Evans AL, Bryant J, Skepper J, Smith SK, Print CG, and CharnockJones DS: Vascular development in embryoid bodies: quantification of transgenic intervention and antiangiogenic treatment. Angiogenesis $2007,10: 217-226$

37. Bruner-Tran KL, Zhang Z, Eisenberg E, Winneker RC, and Osteen KG Down-regulation of endometrial matrix metalloproteinase-3 and -7 expression in vitro and therapeutic regression of experimental endometriosis in vivo by a novel nonsteroidal progesterone receptor agonist, tanaproget. J Clin Endocrinol Metab 2006, 91:1554-1560

38. Carlsson G, Gullberg B, and Hafstrom L: Estimation of liver tumor volume using different formulas - an experimental study in rats. $J$ Cancer Res Clin Oncol 1983, 105:20-23

39. Krikun G, Schatz F, Mackman N, Guller S, Demopoulos R, and Lockwood CJ: Regulation of tissue factor gene expression in human endometrium by transcription factors Sp1 and Sp3. Mol Endocrinol 2000, 14:393-400

40. Lockwood CJ, Nemerson Y, Krikun G, Hausknecht V, Markiewicz L, Alvarez M, Guller S, and Schatz F: Steroid-modulated stromal cell tissue factor expression: a model for the regulation of endometrial hemostasis and menstruation. J Clin Endocrinol Metab 1993, 77:1014-1019

41. Lockwood CJ, Murk W, Kayisli UA, Buchwalder LF, Huang ST, Funai EF, Krikun G, and Schatz F: Progestin and thrombin regulate tissue factor expression in human term decidual cells. J Clin Endocrinol Metab 2009, 94:2164-2170

42. Arici A, Seli E, Zeyneloglu HB, Senturk LM, Oral E, and Olive DL: Interleukin-8 induces proliferation of endometrial stromal cells: a po- tential autocrine growth factor. J Clin Endocrinol Metab 1998, 83:1201-1205

43. Taylor RN, Ryan IP, Moore ES, Hornung D, Shifren JL, and Tseng JF: Angiogenesis and macrophage activation in endometriosis. Ann NY Acad Sci 1997, 828:194-207

44. Parry GC, and Mackman N: Transcriptional regulation of tissue factor expression in human endothelial cells. Arterioscler Thromb Vasc Biol 1995, 15:612-621

45. Reny JL, Laurendeau I, Fontana P, Bieche I, Dupont A, Remones V, Emmerich J, Vidaud M, Aiach M, and Gaussem P: The TF-603A/G gene promoter polymorphism and circulating monocyte tissue factor gene expression in healthy volunteers. Thromb Haemost 2004 91:248-254

46. Shinohara $\mathrm{Y}$, Iwasaki $\mathrm{H}$, Ota $\mathrm{N}$, Nakajima $T$, Kodaira $\mathrm{M}$, Kajita $\mathrm{M}$, Shiba T, and Emi M: Novel single nucleotide polymorphisms of the human nuclear factor kappa-B 2 gene identified by sequencing the entire gene. J Hum Genet 2001, 46:50-51

47. Sun XF, and Zhang H: NFKB and NFKBI polymorphisms in relation to susceptibility of tumour and other diseases. Histol Histopathol 2007, 22:1387-1398

48. Bora PS, Hu Z, Tezel TH, Sohn JH, Kang SG, Cruz JM, Bora NS, Garen $\mathrm{A}$, and Kaplan HJ: Immunotherapy for choroidal neovascularization in a laser-induced mouse model simulating exudative (wet) macular degeneration. Proc Natl Acad Sci USA 2003, 100:2679-2684

49. Tezel TH, Bodek E, Sonmez K, Kaliappan S, Kaplan HJ, Hu Z, and Garen A: Targeting tissue factor for immunotherapy of choroidal neovascularization by intravitreal delivery of factor VII-Fc chimeric antibody. Ocul Immunol Inflamm 2007, 15:3-10

50. D'Hooghe TM, Kyama CM, Chai D, Fassbender A, Vodolazkaia A, Bokor A, and Mwenda JM: Nonhuman primate models for translational research in endometriosis. Reprod Sci 2009, 16:152-161

51. Schenken RS: Delayed diagnosis of endometriosis. Fertil Steril 2006 , 86:1305-1306; discussion 1317

52. Hadfield R, Mardon H, Barlow D, and Kennedy S: Delay in the diagnosis of endometriosis: a survey of women from the USA and the UK. Human Reprod 1996, 11:878-880

53. Mihalyi A, Simsa P, Mutinda KC, Meuleman C, Mwenda JM, and D'Hooghe TM. Emerging drugs in endometriosis. Expert Opin Emerging Drugs 2006, 11:503-524

54. Tang Y, Borgstrom P, Maynard J, Koziol J, Hu Z, Garen A, and Deisseroth $A$ : Mapping of angiogenic markers for targeting of vectors to tumor vascular endothelial cells. Cancer Gene Therapy 2007 14:346-353 